\title{
Retrospective study of adenovirus in autopsied pulmonary tissue of pediatric fatal pneumonia in South China Zhi-Ying Ou ${ }^{\dagger 1}$, Qi-Yi Zeng ${ }^{\dagger 1,2}$, Feng-Hua Wang ${ }^{1}$, Hui-Min Xia ${ }^{1}$, Jun-Peng Lu ${ }^{3}$, Jian-Qing Xia ${ }^{1}$, Si-Tang Gong1, Li Deng1, Jian-Tao Zhang ${ }^{1}$ and Rong Zhou*1
}

\begin{abstract}
Address: ${ }^{1}$ Guangzhou Children's Hospital, Guangzhou Medical College, Guangzhou, 510120, Guangdong, PR China, ${ }^{2}$ Department of Pediatrics Nangfang Hospital, Southern Medical University, Guangzhou, 510301, Guangdong, PR China and ${ }^{3}$ College of Veterinary Medicine, South China Agricultural University, Guangzhou, 510642, Guangdong, PR China

Email: Zhi-Ying Ou - ouzhiying@yahoo.com.cn; Qi-Yi Zeng - gzcentralab@yahoo.com.cn; Feng-Hua Wang - wangfh@hotmail.com; HuiMin Xia - huiminxia@ hotmail.com; Jun-Peng Lu - refuse@163.com; Jian-Qing Xia - xjq@gzch.org; Si-Tang Gong - sitangg@hotmail.com; Li Deng - drdengli@126.com; Jian-Tao Zhang - jtzhang@sina.com; Rong Zhou* - zhou3218@yahoo.com

* Corresponding author †Equal contributors
\end{abstract}

Published: 2I September 2008

BMC Infectious Diseases 2008, 8:122 doi:10.1186/1471-2334-8-122
Received: 12 December 2007

Accepted: 21 September 2008

This article is available from: http://www.biomedcentral.com/I47/-2334/8/I22

(c) 2008 Ou et al; licensee BioMed Central Ltd.

This is an Open Access article distributed under the terms of the Creative Commons Attribution License (http://creativecommons.org/licenses/by/2.0), which permits unrestricted use, distribution, and reproduction in any medium, provided the original work is properly cited.

\begin{abstract}
Background: Adenovirus are the important pathogen of pediatric severe pneumonia. The aim of this study is to analyze the infection, subtype and distribution of adenovirus in autopsied pulmonary tissue of fatal pneumonia in infants and children, and the relationships between adenovirus infection and respiratory illness in South China.

Methods: Nested PCR was performed on DNA extracted from autopsied lung tissue from patients who died of severe pneumonia, and the positive nested PCR products were cloned and sequenced. The adenovirus in autopsied pulmonary tissue was also analyzed by immunohistochemistry assay in a blind way.

Results: In the 175 autopsied pulmonary tissues, the positive percentage of adenovirus was $9.14 \%$ $(16 / 175)$ and $2.29 \%$ (4/175) detected with nested PCR and immunohistochemistry, respectively. There are three cases of adenovirus serotype 3 , twelve cases of adenovirus serotype 4 and one case of serotype $4 \mathrm{I}$ determined by sequencing of the cloned positive nested PCR products.
\end{abstract}

Conclusion: Adenovirus is an important cause of severe pneumonia, and these data suggest that adenovirus serotype 4 might be an important pathogen responsible for the fatal pneumonia in Guangzhou, South China.

\section{Background}

Adenoviruses (AdVs) are non-enveloped, doublestranded DNA viruses that vary in size from 70 to $100 \mathrm{~nm}$. They are the common pathogens of respiratory tract, gastrointestinal tract, urethral canal and eye characterized by self-limiting infection[1]. AdVs are endemic in children, and infections usually occur at young age ( 5 months to 6 years)[2,3]. AdVs can incite continuous and intensive infection with the utilization of a detective or compromised immune system sometimes resulting in lethality[4]. The clinical symptoms of AdVs infection are atypical and variable, including amygdalitis, conjunctivitis, pneumonia, gastroenteritis, hepatitis and hemorrhagic cystitis[2,3,5-9]. Local infections generalize in some cases 
and then have a mortality rate of up to $60 \%[2,3,5,7,8,10]$. AdVs are the important pathogen of pediatric severe pneumonia, which can cause large-scale epidemics. For example, AdVs pneumonia was the most common pneumonia in Beijing and Shanghai area of China from the 1950s to 1960s characterized by complications, high mortality, but the incidence declined in the late 1980s with some diverging occasionally [11-13]. As reported from Zhang[14], viral pneumonia is mainly caused by respiratory syncytial virus (RSV) and AdVs in large cities, with an infection rate of $10 \%-15 \%$ respectively[15]. Adenovirus accounted for $32.2 \%$ of severe pneumonia as indicated from the report of Liu et al[16].

The clinical features of AdVs pneumonia in infants and children are emergency onset, violent background, and persistent ardent fever up to $40^{\circ} \mathrm{C}$. Severe toxic symptoms all over the body occur in the early stages of infections, with weak consciousness, lethargy and cataphora. Respiratory symptoms include cough, asthma and anhelation. Cardiac and respiratory failures are common occurrences, as well as the fatality rates up to $20 \%-25 \%$. The aim of this study is to analyze the AdVs infection associated with severe pediatric pneumonia and the relationships between AdVs infection and respiratory diseases. These data should provide information towards more accurate diagnosis and treatment of pediatric severe pneumonia.

\section{Methods}

\section{Clinical samples}

One hundred and seventy five cases of pediatric fatal pneumonia archived paraffin-embedded autopsied pulmonary tissues collected from July 1988 to January 2005 were analyzed in this study. All the samples were collected from Guangzhou Children's Hospital which included 114 male and 61 female specimens, aged one month to 10 years old, with an average age of 17.6 months. All the cases were pathologically diagnosed for interstitial or bronchial pneumonia in autopsia, among which 18 cases were pathologically diagnosised with AdVs pneumonia according to the cytopathology. The specimens were stored at room temperature until the viral genomic DNA was extracted and immunohistochemistry (IHC) was performed.

\section{Immunohistochemistry}

Autopsied tissues were fixed in $10 \%$ buffered formalin for 24-48 hours, embedded in paraffin, and sectioned $4 \mu \mathrm{m}$ thick onto Vectabond treated slides. Tissues were deparaffinized in two changes of xylene and re-hydrated from graded alcohols to distilled water. Tissues were quenched with 3\% hydrogen peroxide for one hour. For the primary antibody, mouse-derived monoclonal antibodies against human AdVs hexon (Huayin, Guangzhou, China) were used at a 1:500 dilution and incubated for 1 hour at $37^{\circ} \mathrm{C}$.
Horseradish peroxidase (HRP) labeled secondary antibody included in the MaxVision ${ }^{\mathrm{TM}}$ HRP-Polymer antimouse/rabbit IHC kit (MaxVision, Fuzhou, China), was applied for 30 minutes at room temperature, followed by 2-6 minutes incubation at room temperature with diaminobenzidine (Dako Corp., CA) for color development. Slides were counterstained with hematoxylin $\left(\right.$ Harleco $\left.^{\circledast}\right)$, washed, and dehydrated with alcohol and xylene. Slides were mounted with a cover slip using a permanent mounting medium (Permount).

\section{DNA extraction}

DNA was extracted from paraffin-embedded pulmonary tissue using DNeasy Kit for Purification of Total DNA from Animal Tissue (Qiagen, Germany). The procedures were as follows: 1) Five to eight pieces of $10 \mu \mathrm{m}$ thick section of paraffin-embedded lung tissue were placed into $1200 \mu \mathrm{l}$ xylene, vortexed vigorously and centrifuge at $14,000 \mathrm{rpm}$ for $3 \mathrm{~min}$ at room temperature. 2) The supernatant was removed and $1200 \mu \mathrm{l}$ ethanol (96\%-100\%) was added to the pellet to remove the residual xylene and mixed gently by vortex, the sample was centrifuged at $16,000 \mathrm{rpm}$ for $5 \mathrm{~min}$ at room temperature and the supernatant removed. 3) Step 2 was repeated followed by continuation with the manufacturer's protocol: "Purification of Total DNA from Animal Tissues". Finally, DNA was eluted with $200 \mu \mathrm{l}$ Buffer AE.

\section{Nested PCR conditions}

Nested PCR on extracted DNA was performed with degenerate primers according to Allard et al[17], the primers are located in the hexon gene. Five microliters of DNA was amplified in $25 \mu \mathrm{l} 1 \times$ PCR buffer containing $200 \mu \mathrm{mol} / \mathrm{L}$ of each deoxynucleoside triphosphate (dNTP), $1.5 \mathrm{mmol} /$ $\mathrm{L}$ of $\mathrm{Mg}^{2+}, 1 \mathrm{U}$ of Taq DNA polymerase (Promega, USA), and $0.2 \mu \mathrm{mol} / \mathrm{L}$ of each primer. The first round amplification was performed by using a T3 thermocycler (Biometra, Germany) under the following conditions: Initial denaturation at $95^{\circ} \mathrm{C}$ for $5 \mathrm{~min}$, followed by 30 cycles of $95^{\circ} \mathrm{C}$ for $30 \mathrm{~s}, 50^{\circ} \mathrm{C}$ for $30 \mathrm{~s}$, and $72^{\circ} \mathrm{C}$ for $30 \mathrm{~s}$, and a final extension at $72^{\circ} \mathrm{C}$ for $7 \mathrm{~min}$. The second round amplification was amplified with $3 \mu \mathrm{l}$ of first round PCR product and was performed with the following conditions: Initial denaturation at $95^{\circ} \mathrm{C}$ for $5 \mathrm{~min}$, followed by 35 cycles of $95^{\circ} \mathrm{C}$ for $30 \mathrm{~s}, 55^{\circ} \mathrm{C}$ for $30 \mathrm{~s}$, and $72^{\circ} \mathrm{C}$ for $30 \mathrm{~s}$, and a final extension at $72^{\circ} \mathrm{C}$ for $7 \mathrm{~min}$. The PCR products were separated by electrophoresis through a $2 \%$ agarose gel and viewed under viltalight lamp.

\section{DNA cloning and sequencing}

The second round PCR products were purified by phenolchloroform (1:1) extraction, precipitated with ethanol, and dissolved in water. The $171 \mathrm{bp}$ products were cloned into pMD 18-T Simple Vector (TaKaRa, Japan) according 
to the manufacturer's instruction. Cloned plasmids were sequenced in BioAsia Corporation (Shanghai, China).

\section{Blind Assay}

Both nested PCR and IHC were carried out for all the samples. IHC results were confirmed by two pathologists. Positive results of nested PCR and IHC were repeated three times to confirm the results.

\section{Data analysis}

All data were analysed by using SPSS for Windows version 11.0 (Chicago, IL, USA).

\section{Ethical aspects}

Use of clinical samples in this research was authorised by the ethic committee of the Guangzhou Children's Hospital. The informed consents were signed with the guardians of the children studied. The study corresponded to the ethic committee standards of Guangzhou Children's Hospital.

\section{Results}

\section{Immunohistochemistry}

The representative positive results of AdVs infected pulmonary tissue are shown in Figure 1. The position of virus infection is distinct, locating in the cytoplasm of acinous cells in the mucilaginous glands under the tunica mucosa bronchiorum. Only 4 cases showed AdVs positive resulting in a positive rate of $2.29 \%(4 / 175)$.

\section{Nested PCR}

DNA was extracted from 175 autopsied pulmonary tissues and nested PCR was performed with degenerate primers. The results for 12 of the 175 samples are shown in Figure 2 . The presence of the $171 \mathrm{bp}$ target band was seen in 16/
175 samples. All the results are repeated three times with the same extraction DNA. Therefore, AdVs was detected in autopsied pulmonary tissue at a positive rate of $9.14 \%$.

\section{DNA cloning and sequencing}

The positive nested PCR products were purified, cloned and sequenced. The sequences acquired were subjected to BLAST analysis in Genbank. The results of this analysis were three cases (18.75\%) of AdVs serotype 3, twelve cases (75\%) of AdVs serotype 4 and one case (6.25\%) of AdVs serotype 41 (Table 1).

\section{Comparison of pathological diagnosis, IHC and nested PCR}

Nested PCR and IHC were blindly assayed for all the autopsied pulmonary tissues. Four cases were positive for both assays, 159 cases were negative for both assays, and 12 cases were positive in nested PCR but negative in IHC. There is no case in which the PCR results were negative and IHC results were positive (Table 2). Results of pathological diagnosis, nested PCR and IHC were also compared. There was only one case positive in three assays, 2 cases were positive in pathological diagnosis and nested PCR but negative in IHC, 15 cases were positive in pathological diagnosis but negative in nested PCR and IHC, 10 cases were negative in pathological diagnosis and IHC but positive in nested PCR, 3 cases were negative in pathological diagnosis but positive in nested PCR and IHC. The others were all negative in three assays (Table 3 ).

\section{Discussion}

AdVs were the important agent of pediatric severe pneumonia, which can induce large-scale epidemics. AdVs infection was one of the common causes of pneumonia in Beijing and Shanghai area of China from the 1950s to
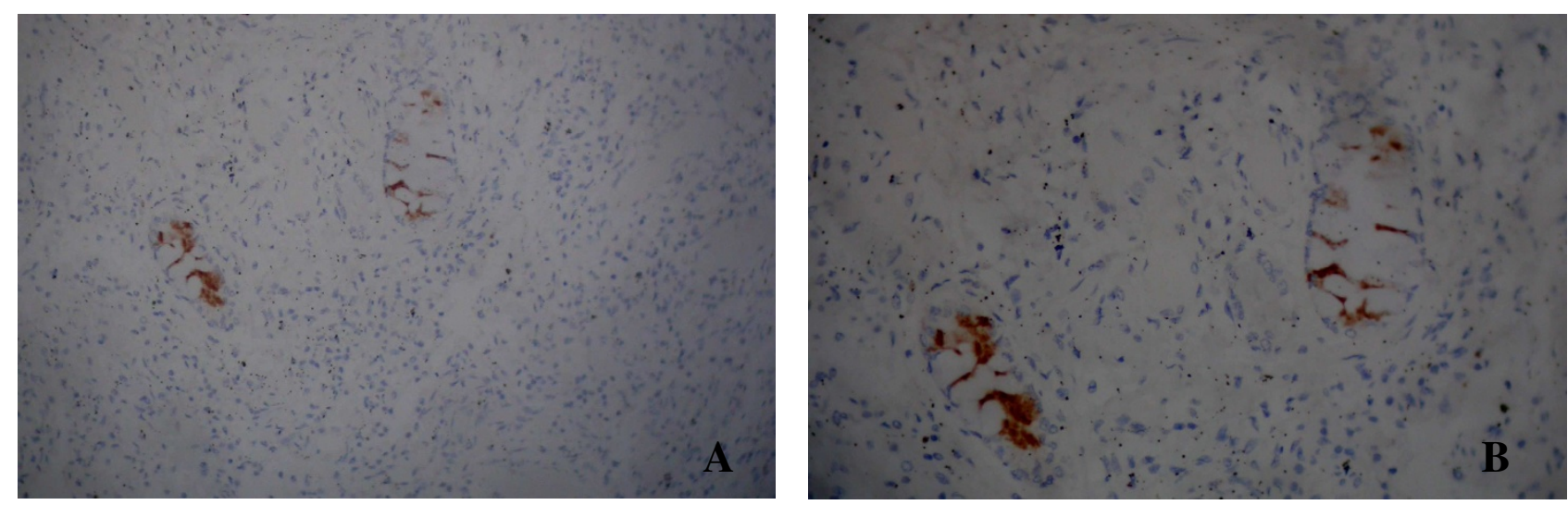

Figure I

Immunohistochemistry results of autopsied pulmonary tissue. Labeling: A: $100 \times($ positive), B: $200 \times($ positive). 


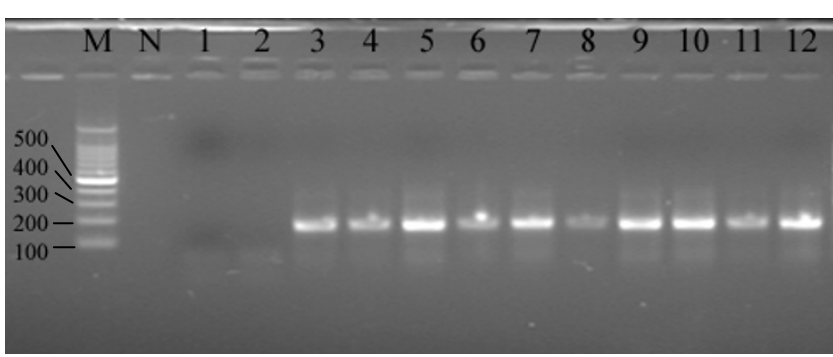

Figure 2

Agarose gel electrophoresis analysis of nested PCR products in autopsied pulmonary tissues. Labeling: $M$ : DNA molecular marker, $\mathrm{N}$ : negative control, I-2: negative cases, 3-I2: positive cases.

1960s, with more complications and high fatality rates. In the late 1980s, the incidence declined with only some diverging cases.

RSV and AdVs are the major agents of viral pneumonia in large cities, accounting for 10\%-15\% respectively[14]. AdVs accounts for $32.2 \%$ of severe pneumonia according to Liu et al[16]. The results of virus separation in cell culture in our hospital from 1975 to 1985 showed that the years 1976, 1979, and 1980 were the highly epidemic years (data not shown). Results from ELISA and virus cultures for respiratory disease from January 2003 to December 2005 in our hospital showed the AdVs positive rate was $8.5 \%(70 / 824)$ (data not shown). Our results show that AdVs infection in autopsied severe pneumonia pulmonary tissues was $9.14 \%$. Taken together, these observations indicate that AdVs is still a major agent of severe pneumonia and it plays an important role in lethal severe pneumonia in Guangzhou area. Therefore, we must strengthen the surveillance for AdVs and national recommendations for AdVs vaccine development in future.

AdVs are responsible for much of the public incidence of pneumonia. The 51 different serotypes of human AdVs are classified into six subgenera (subgenera A to F) on the basis of erythrocyte coagulation characteristics, oncogenicity and DNA sequence[2]. The clinical pathogenicity differs among different adenovirus serotypes. The AdVs

Table I: Distribution of adenovirus serotypes in autopsied pulmonary tissue of severe pneumonia

\begin{tabular}{ccc}
\hline AdV serotype & Cases & Percentage in AdV Positive Cases \\
\hline 3 & 3 & $18.75 \%$ \\
4 & 12 & $75 \%$ \\
41 & 1 & $6.25 \%$ \\
\hline
\end{tabular}

Table 2: Results of coincidence of nested PCR and IHC in AdV detection in autopsied pulmonary tissue of severe pneumonia

\begin{tabular}{ccc}
\hline & PCR Positive & PCR Negative \\
\hline IHC Positive & $4(2.29 \%)$ & $0(0 \%)$ \\
IHC Negative & $12(6.86 \%)$ & $159(90.86 \%)$ \\
\hline
\end{tabular}

types within a subgenus are similar in their tropisms, pathogenicity, and tendencies to cause a latent infection and epidemics[17,18]. Overall frequency of AdVs as the cause of nonbacterial pneumonia in children is less than that of RSV and parainfluenza virus type 3, but an alarming number of fatal illnesses have been noted. Severe and fatal illnesses in infants and children have been noted in association with AdVs types 1, 2, 3, 4, 5, 7a, 7h, 7i, 8, 19, 21,35 , and the intermediate strain $21 / \mathrm{H} 21+35$ [19]. Respiratory illness is mainly caused by AdVs serotype 3, 4, 7 , 14,21 , and to a less extent by serotypes 1, 2, 5 and $6[6,18]$. Pediatric pneumonia is mainly caused by AdVs serotypes 1, 2, 3 and 7, whereas serotypes 4 and 7 are mainly responsible for adult pneumonia. According to several reports, serotypes 3, 4, 7 and 21 usually cause large scale respiratory illnesses and fulminate prevalence events, causing respiratory illness such as severe lethal pneumonia and pharyngoconjunctival fever [20,21]. Our data identified 12 cases of AdVs serotype 4 from 175 autopsied pulmonary tissues, suggesting that AdVs serotype 4 , which accounts for $75 \%$ in the positive cases, might be an important serotype responsible for pediatric fatal pneumonia in the Guangzhou area which locates in South China, and therefore it is important that we pay close attention to the detection of AdVs serotype 4 in pediatric severe pneumonia.

Our results from nested PCR and IHC are in concordance. Twelve PCR positive cases are negative in IHC, suggesting that nested PCR is a more sensitive method for the detection of AdVs and also reflecting the limitation of IHC in pathogen detecting. Results of pathological diagnosis, AdVs nested PCR and IHC were compared. The cases were

Table 3: Results of comparison of pathological diagnosis, nested PCR and IHC in $\mathbf{I 7 5}$ cases of autopsied pulmonary tissue of severe pneumonia

\begin{tabular}{cccc}
\hline Pathologic diagnosis & Nested PCR & IHC & Number of Cases \\
\hline+ & + & + & 1 \\
- & + & + & 3 \\
+ & + & - & 2 \\
- & + & - & 10 \\
+ & - & - & 15 \\
- & - & - & 144
\end{tabular}


all negative or positive in the three assays, or positive in pathological diagnosis, nested PCR but negative in IHC representing the coincidental cases with a concordance percentage of $84 \%(147 / 175)$, while others were not as concordant (Table 3). The unmatched results in the three methods indicated that PCR is a more sensitive assay than IHC. Pathological diagnosis of cell morphologic is to a large extent dependent on observation under the microscope with the naked eyes, therefore, the standards are subjective in some degree, which can result in poor specificity, high misdiagnosis or missed rate. Thus, pathological diagnosis has limitations compared with the sensitive, specific and reproducibility of nested PCR assay at the molecular level. As for the archived paraffin-embedded autopsied pulmonary tissues stored from 1988 to 2005 for PCR, the 16 positive samples distribute from 1994 to 2005 but none before 1993. The 15 cases of positive pathological diagnosis without PCR positivity (Table 3 ), it is possible that these cases or a number of them were older than 15 years, i.e. originating from before 1993, Perhaps the viral DNA in the older samples stored at room temperature more than 15 years degraded seriously and the materials is too old to be assayed by PCR. Concerning severe pneumonia in the clinic, we must strengthen the pathogen detection based on PCR technology, such as fluorescent quantitative PCR, nested fluorescent quantitative PCR, and nested PCR in order to provide more accurate and reliable molecular diagnostics results for pathogen identification underlying the disease and thus avoid the abuse of antibiotics.

\section{Conclusion}

Adenovirus is an important cause of severe pneumonia, and these data suggest that adenovirus serotype 4 might be an important pathogen responsible for the fatal pneumonia in Guangzhou, South China.

\section{Competing interests}

The authors declare that they have no competing interests.

\section{Authors' contributions}

ZYO has been involved in designing the study and drafting the manuscript or revising it critically for important intellectual content. QYZ has made substantial contributions to conception and design. FHW carried out the IHC experiment as a pathologist. HMX participated in the sequence alignment and polished the manuscript. JPL carried out the nested PCR. JQX participated in the IHC experiment. STG participated in the design of the study. LD participated in its design and performed the statistical analysis. JTZ carried out the IHC experiment as a pathologist. RZ has given final approval of the version to be published. All authors read and approved the final manuscript.

\section{Acknowledgements}

This work was supported by the Tackle Key Program in science and technology (grant no. 2005ZI-EOI I5 and 2006Z3-E033I) from the Science and Technology Bureau of Guangzhou, by the Science and Technology Program (grants no. 2006-YB-077) from Health Bureau of Guangzhou, and by the Doctoral Initiating Project of Guangzhou Women \& Children Medical Center, Guangzhou, Guangdong Province, China.

\section{References}

I. Chmielewicz B, Benzler J, Pauli G, Krause G, Bergmann F, Schweiger $B$ : Respiratory disease caused by a species $B 2$ adenovirus in a military camp in Turkey. J Med Virol 2005, 77(2):232-237.

2. Walls T, Shankar AG, Shingadia D: Adenovirus: an increasingly important pathogen in paediatric bone marrow transplant patients. Lancet Infect Dis 2003, 3(2):79-86.

3. Gu Z, Belzer SW, Gibson CS, Bankowski MJ, Hayden RT: Multiplexed, real-time PCR for quantitative detection of human adenovirus. J Clin Microbiol 2003, 4 I ( I 0):4636-464I.

4. Hierholzer JC: Adenoviruses in the immunocompromised host. Clin Microbiol Rev 1992, 5(3):262-274.

5. Pham TT, Burchette JL, Hale LP: Fatal disseminated adenovirus infections in immunocompromised patients. Am J Clin Pathol 2003, I 20(4):575-583.

6. Heim A, Ebnet C, Harste G, Pring-Akerblom P: Rapid and quantitative detection of human adenovirus DNA by real-time PCR. J Med Virol 2003, 70(2):228-239.

7. Echavarria M, Forman M, Ticehurst J, Dumler JS, Charache P: PCR method for detection of adenovirus in urine of healthy and human immunodeficiency virus-infected individuals. J Clin Microbiol I998, 36(I I):3323-3326.

8. Lion T, Baumgartinger R, Watzinger F, Matthes-Martin S, Suda M, Preuner $S$, et al:: Molecular monitoring of adenovirus in peripheral blood after allogeneic bone marrow transplantation permits early diagnosis of disseminated disease. Blood 2003, I02(3): I | |4- | I 20.

9. Echavarria M, Forman M, Van Tol MJ, Vossen JM, Charache P, Kroes $A C$ : Prediction of severe disseminated adenovirus infection by serum PCR. Lancet 200I, 358(9279):384-385.

10. Teramura T, Naya M, Yoshihara T, Kanoh G, Morimoto A, Imashuku $S$ : Adenoviral infection in hematopoietic stem cell transplantation: early diagnosis with quantitative detection of the viral genome in serum and urine. Bone Marrow Transplant 2004, 33(1):87-92.

II. Zhu JM: Pathogen analysis of pediatric virological pneumonia. Acta Microbiol Sin 1963, 9:20.

12. Wang HY: Pathogen study of adenovirus pneumonia in Beijing area from 1960 to 1964. Beijing MedJ 1965, 2:56.

13. Zhao JM, Wang ZL, Zhang ZJ: Adenovirus analysis in pediatric pneumonia of Beijing area during the year of 1964-1967 and 1974-1977. Chin J Pediatr 1980, I8(3):|49-I5I.

14. Zhang ZJ: Current situation and strategy of viral pneumonia. Chin J Pediatr 1997, 35(8):397.

15. Liu CG, Wang F, Wan LT: Investigation of viral pathogen in cases of pneumonia of newborn. Chin J Neonatol 1997, I 2(5): 196.

16. Liu XY, Jiang ZF: Pathogens analysis of 31 cases of pediatric severe community acquired pneumonia. Chin J Pract Pediatr 2005, 20( I 2):749-750.

17. Allard A, Albinsson B, Wadell G: Rapid typing of human adenoviruses by a general PCR combined with restriction endonuclease analysis. J Clin Microbiol 2001, 39(2):498-505.

18. Schmitz H, Wigand R, Heinrich W: Worldwide epidemiology of human adenovirus infections. Am J Epidemiol 1983, I I 7(4):455-466.

19. Feigin RD, Cherry JD, Demmler GJ, Kaplan SL: Textbook of pediatric infectious diseases. 5th edition. Philadelphia: Saunders; 2004:215-235.

20. Kolavic-Gray SA, Binn LN, Sanchez JL, Cersovsky SB, Polyak CS, Mitchell-Raymundo F, et al.: Large epidemic of adenovirus type 4 infection among military trainees: epidemiological, clinical, and laboratory studies. Clin Infect Dis 2002, 35(7):808-8I8.

21. Chen HL, Chiou SS, Hsiao HP, Ke GM, Lin YC, Lin KH, et al.: Respiratory adenoviral infections in children: a study of hospital- 
ized cases in southern Taiwan in 2001-2002. J Trop Pediatr 2004, 50(5):279-284.

\section{Pre-publication history}

The pre-publication history for this paper can be accessed here:

http://www.biomedcentral.com/1471-2334/8/122/pre pub

Publish with Bio Med Central and every scientist can read your work free of charge

"BioMed Central will be the most significant development for disseminating the results of biomedical research in our lifetime. " Sir Paul Nurse, Cancer Research UK

Your research papers will be:

- available free of charge to the entire biomedical community

- peer reviewed and published immediately upon acceptance

- cited in PubMed and archived on PubMed Central

- yours - you keep the copyright 